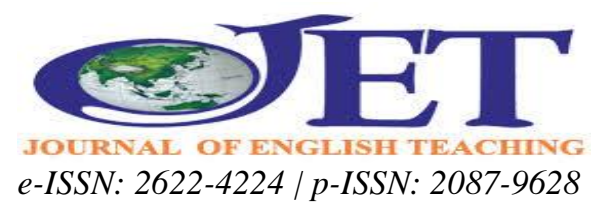

\title{
A Literature Review on Remedial Reading Teachers: The Gaps in the Philippine Context
}

\author{
Al Ryanne G. Gatcho \\ gatcho.arg@pnu.edu.ph \\ Assistant Professor, College of Graduate Studies and Teacher Education Research \\ Philippine Normal University \\ Judy C. Bautista \\ bautista.jc@pnu.edu.ph \\ Assistant Professor, College of Graduate Studies and Teacher Education Research \\ Philippine Normal University
}

D0I: https://doi.org/10.33541/jet.v5i2.1063

\begin{abstract}
Remedial reading teachers are forerunners in elevating the reading achievement of students in schools. In the Philippines, there has been a continual enrichment of the reading skills of struggling readers through the initiatives of remedial reading teachers. However, the country does not have clear policies on the identities, roles, challenges, and needs of such teachers. This paper presents a review of the literatures on remedial reading teachers. The results revealed that remedial reading teachers performed various roles in schools and that the cultivation of the roles and duties of remedial reading teachers rely so much on different factors, some of which are knowledge and the skills that they have, philosophical views in education and the whole school community, the rapport that remedial reading teachers have with their colleagues, the support of the administrators to their personal and career developments, and provisions of the local government. It was also evident in the review that there is a scarcity of literature and studies regarding remedial reading teachers in the Philippines, thus, suggesting to explore on the what's and the how's of remedial reading teachers in a hope of creating clear policies that will strengthen their identities and support their professional developments.
\end{abstract}

Keywords: reading, remedial reading, literacy education, teacher development

\section{INTRODUCTION}

A remedial reading teacher in the Philippines or a reading specialist in the U.S. and majority of the European countries is a professional teacher who has an adept background and training in honing the reading abilities of students in general and assists struggling readers to improve themselves (International Reading Association [IRA], 2018.). Although majority of the work of a remedial reading teacher revolves on providing instruction for struggling readers, he or she is also tasked to serve as a focal person to teachers to further hone their pedagogical practices related to literacy education.

In America, the competencies and requirements of being a remedial reading teacher are set by the publication Standards for Reading Professionals (IRA, 1998). The 
stipulated standards are bases for differentiating remedial reading teachers from regular reading classroom teachers. Since they are considered education professionals, it is clear in the Standards that those without appropriate credentials, degrees, trainings, and backgrounds and those who cannot show advanced skills in literacy education are not legible to be remedial reading teachers. If classroom teachers cultivate their skills in teaching reading, a remedial reading teacher needs a serious, systematic and meticulous groundwork in order to become one. Furthermore, the Standards requires remedial reading teachers to possess graduate degrees in literacy education in order to preserve and to enhance their professional integrity. They need to have affluent classroom experiences in order to exude flexibility in handling different students with reading difficulties and must have the strong credibility to maintain professionalism at all times. Because of the important roles vested to a remedial reading teacher, every school in the US makes it a point to have one or two remedial reading teachers and therefore, they have available allocations for such position.

In the Philippines, the problem of students in reading is not a new issue. In fact, certain studies reveal that the reading problems of Filipino students seemed to be perennial (Alayon, 2014; Habagat \& Rizon, 2012; Lalunio, 1994; Miguel, 2007; Montalban, 2010; Umali, 2016). Due to such problems, reading and literacy instruction have always been the top priority in all Philippine curricula. Umali (2016) labels that reading instruction in the Philippines can be distinguished into two facets: (1) the regular reading class which is embedded in the standard curriculum, and (2) the remedial reading class which is a separate subject given to those students who need help in correcting and improving their reading difficulties. The remedial reading class in the Philippines is a pull-out type since it is not integrated within the regular reading class of the students.

The practice of remedial reading has been in the limelight for a long time in the Philippine education sector. In fact, the study of Genero (1976) presents how elementary schools and high schools in the country devised their own remedial reading programs to assist struggling readers. He explains that the principals of the schools encourage their teachers to assess their students reading level so that they can provide the proper interventions for them. Although, remediation for struggling readers has been practiced in the Philippines for decades, its optimization has reached its prime only through the Department Order (DO) 45, series of 2002 - Reading Literacy Program in the Elementary Schools and DO 27, s. 2005- Remedial Instruction Programs in High School of the Philippine Department of Education (DepEd).

Rio (2007) enumerates the typical duties of remedial teachers in the Philippines: (1) work very closely with the principal, students' teacher and the rest of the staff, (2) assess the students' levels of functioning in reading, (3) provide remediation for students who are struggling in reading their first or second language, (4) conduct the pre-tests and post-tests to see where the students' strengths and weaknesses are, and (5) work one-on-one with any of the students who are struggling in those two main areas of academia. Additionally, she adds these outside-the-classroom duties of remedial reading teachers: (1) work cooperatively with the staff, especially during staff development and trainings, and create activities based on the curriculum that will help the remedial students, (2) maintain the data collection for the classroom teachers, (3) manage students' records in a timely and appropriate way, (4) assist the staff in any other way, and (5) counsel children with special needs and work closely with their parents. These 
duties were based upon Rio's experiences as a remedial reading teacher in the public school

Although Rio (2017) was able to enumerate the typical roles of a remedial reading teacher, its status as a professional position in schools is still unrecognized in the Philippines. Although there are teachers who provide assistance and support to students with reading difficulties, there is no existing allocations for such position. Hence, being a remedial reading teacher is considered an extra workload for teachers and is not compensated for doing the roles and responsibilities entrusted to them as opposed to the recognition given to this job in the US and other foreign counties. Not only this, the qualifications of a remedial reading teacher is not even concrete and clear. In fact, the usual practice of local schools is that the classroom reading teachers are also the remedial reading teachers of identified students with reading difficulties. Even though the DepEd provides trainings for remedial reading teachers, the agency doesn't have any uniform, clear and organized guidelines as to how remedial reading instruction should be done in schools (Batan, 2016).

This review seeks to unravel the gaps with regard to the lack of recognition for the essential roles played by remedial reading teachers as professionals in the Philippine schools. With the strong emphasis given to reading and literacy education in the Philippines, there is a need for every school to encourage their teachers to serve as remedial reading teachers. This review seeks to clarify all aspects that refer to the nature of the work of a remedial reading teacher to provide a foundational understanding of what they are going through. Lastly, it is hoped that through the discussion of these relevant literatures, there will be more studies which seek to concretize the identities of a remedial reading teacher in the Philippines will be explored. Hence, leading to concrete policies and guidelines of the requirements and preparation for those teachers who wish to become one.

\section{DISCUSSION}

A vast majority of research studies have examined remedial reading teachers in the elementary level in contrast to teachers in the secondary level. This is mainly due to the significance of deterring any probable reading impediments a student can encounter and the continuous budget allotted to elementary institutions (Frost, 2007). Furthermore, according to Ruddell (1993), the inadequacy of studies related to secondary teachers is also attributed to the adversity of employing experienced and proficient remedial reading teachers. Subsequently, secondary teachers qualified for a remedial reading subject have been insufficient (Bean et al., 2002). Moreover, there is a need to provide insights regarding the development of teachers to enable further understanding in relation to how the growth of students of reading can also be affected.

Thus, the readings taken in this section are selected to gauge the extent of knowledge of elementary and secondary remedial reading teachers from the contemporary period to the present time. Therefore, the scope of this review of related literature is the following: (1) the character and functions of remedial reading teachers, and (2) the perspectives regarding remedial reading teaching.

\section{Characteristics and Functions of Remedial Reading Teachers}

Remedial reading teachers' duties were pioneered in the 1920s. These are professionals who have an expertise in reading strategies whose duties predominantly revolve around helping learners who have difficulties in reading, hence the name (Bean, 2009). 
Eventually, it has become widespread and institutionalized. Its character and functions, however, are primarily influenced by the educational system of the period and where remedial reading teachers are stationed. Consequently, this led to the fluidity of its system of responsibilities and functions (Frost, 2007). This is further augmented by the lack of training among remedial reading practicioners coupled with the absence of any researches on the subject which added the difficulty of defining the roles and duties of a remedial reading teacher in the early part of the 1950s (Robinson, 1967).

Nevertheless, the study of Robinson (1958) became the foremost research to investigate the various titles referring to a remedial reading professional and deduce the range of roles and functions of a remedial reading teacher pivoting mainly around teachers in the secondary level. He discovered that there were a multitude of labels pertaining to a remedial reading teacher such as: reading specialist, reading supervisor, reading consultant, reading coordinator, director of reading and other various names. His research founded upon by the responses of 401 remedial reading secondary teachers in the United States, did not, however, posit that there was a profound distinction among the aforementioned titles in terms of the duties they accomplish. He classified these similarities in their responsibilities into three categories: diagnosis, teaching, and consulting.

The first one includes not merely the formal or informal measurement of reading proficiency, but also it involves auditory, visual and intelligence tests. The second comprises of mainstream methods in enhancing the reading capabilities of students; in the aspect of remediation, this revolves around students who have significant difficulties in reading. The last one, on the other hand, border around the tasks of conversing with parents about the development of their child, acquire school paraphernalia for reading, and crafting lesson plans. Aside from these, unfortunately, they are also assigned to numerous tasks imposed upon them by their schools.

During the 1960s, the reading field veered away from remedial teaching to preventative reading. It did not, however, change the duties of remedial reading teachers, to wit, they persisted to function in the categorizations set forth by Robinson. In this period, there were a plethora of titles used to define a remedial reading practicioner which proved that the shift to preventative instruction still failed to systematize a label to define the role of reading practicioners (Frost, 2007). Indeed, even in a conference held under the aegis of the International Reading Association (IRA), now known as the International Literacy Association (ILA), various labels were used: college instructor, reading teacher, reading clinician, reading coordinator, and reading consultant (Dietrich, 2007). Expounding it further, a college instructor trains tertiary students in the feature of reading and research writing; a reading teacher renders remedial reading programs to struggling students; a reading clinician helps classroom teachers in assessing cases of remediation to improve planning and its implementation; a reading coordinator acts as the focal person or leader in school-wide reading programs; while a reading consultant collaborates with administrators and teachers in the creation of and execution of reading programs (Kern, 2011). This consequently led to confusion as to how a remedial reading professional must be addressed which stemmed from this non-binding and inadequate role definition. In spite of these varying titles, Moburg (1967) and Bean (2009) contend that an individual who has received education on reading and conducts reading programs is none other than a reading specialist. They further assert that the latter is different from a reading consultant who is neither a teacher nor an administrator, in lieu, is part of the staff who is considered to 
have a specialization in reading instruction. Although Thomas (2009) subscribes to such a definition, he makes no difference between a reading consultant and a reading specialist.

From the 1970s to 1980s, disputes regarding titles and functions of remedial reading teachers magnified as the reading curriculum became integrated in the secondary level (Ruddell, 1993). That is to say, the polarity of their roles consist of improving the literacy of students to acting as advisor to teachers and administrators but never claiming the role of an instructor (Bean, 1997; Bean, 2009). Various studies have regarded that a reading specialist is non-remedial and act principally as consultants; they are labeled as: lead reading teacher, helping teacher, and reading resource teacher (Bean, 2009; Mason \& Palmatier, 1973; Readence, Baldwin, \& Dishner, 1980). On the other hand, Robinson and Petit (2008) define a reading specialist as a reading teacher as they argue that instructors in reading programs should subjectively mold their role and perform in respect to such given meaning. The study of Mosby (2002) supports this as it reveals that from 8, 467 working reading personnel in the U.S., only $25.7 \%$ utilize reading specialist as its job title while $74.3 \%$ adopt other terms. In other words, administrators and teachers are tackling the confusion in role titles by honing the functions of a reading specialist to suffice the inadequacy in their respective institutions.

While the labels of reading specialists persisted to transform, so did their roles. A number of 50 competencies are determined by Gates (2014), 30 are claimed by Bean and Eichelberger (2015), under other conditions, 416 tasks are established by Mosby (2002). Diversely, Hutson et al. (2012) specified eight roles of a reading specialist: remedial teacher, resource person, advisor, evaluator, in-service leader, instructor, investigator, and diagnostician. Bean (2009) also crafted his own concept of the responsibilities of a remedial reading instructor with four divisions: (1) instruction; (2) administration and planning; (3) diagnosis; and (4) resource person for parents, other teachers and principals. His concept, while heavily similar that of Robinson, includes administration and planning. Nonetheless, she posits that remedial reading teachers spend most of their time with students. This only implies that reading specialists perform a variety of roles such as instruction, generation of reading materials, and act as a consultant to teachers and staff (Bean et al., 2010).

The International Literacy Association has also shifted their understanding concerning reading specialists as they acknowledged the various roles of the latter depending on the requirements of the teachers and students. The ILA defined a reading specialist as an expert in reading strategies who has a duty of developing the literacy skills of students especially those who have difficulties in reading (Quatroche et al., 2001). The ILA (2010), nonetheless, determined the key roles of reading specialists: instruction, coaching and leading school-wide literacy programs. This indicates the fluidity of the usage of job titles but with a coherent set of responsibilities.

The first role refers to the assessment and teaching functions of reading specialists. Typically, they provide remedial programs with small number of struggling students yet sometimes they also offer individual instruction (Lipp, 2017). According to Bean (2009), there are three essential elements when teaching students in reading programs - instruction must be: more supporting, clear and comprehensive, and more intensive. In order to cater to the needs of these students, reading specialists should spend $99 \%$ of their time in assessing the strengths and weaknesses of their learners (Bean et al., 2002). This instruction is a one-on-one intervention made for grade one pupils in relation to their reading and writing skills (Tatum, 2004). 
The second and third roles pertain the leadership and collaboration functions of reading specialists. The ILA (2000) partitioned leadership as having three factors: literacy program creation and planning; acting as a resource person; and professional development. However, ILA (2010) compacted in two categorizations: leadership in the school-wide literacy programs and the development of reading and writing programs. Integral to this leadership function is the skill of reading specialists in coaching teachers and students to improve themselves (Vogt \& Shearer, 2007). This is acknowledged by the ILA (2004) as they rendered their pronouncement in relation to reading advisors signifying the value of the latter to subject teachers as they cooperate with one another to develop the reading competencies of the students. In addition, this pronouncement blurs the line between a reading adviser or coach and that of a reading specialist (International Reading Association, 2004).

Walpole and McKenna (2004) further asserts that leadership among faculty teachers is a significant function for reading specialists. This is to say, that they must not have any evaluative duties. However, data have shown that reading specialists have tended to focus on students than teachers (Lipp, 2017). Nevertheless, to achieve this, a reading specialist must have the ability to create feasible goals, a high level proficiency in communication, the capacity to achieve collaboration and a relationship with other teachers based on respect (Bean, 2009).

Thus, a collaboration between remedial reading teachers and subject teachers has gained much prominence as a multitude of studies have established its benefits (Tatum, 2004; Bean, Swan, \& Knaub, 2003; Henwood, 2000; Brownell \& WaltherThomas, 2000; Barry, 1997; Jaeger, 2016; Vacca \& Padak, 1990). This collaboration is emphasized because classroom teachers have extensive knowledge about their students while reading specialists have greater understanding of the literary methods in reading. Hence, by amalgamating the abilities of both teachers and reading specialists, students can gain more.

Reading specialists, albeit their role regarding instruction is perceived as significant, they now perform roles other than teaching (Bean et al., 1990). This is supported by the study of Bean et al. (2010) which finds that reading specialists perform not only assessments in relation to students' level of literacy but they also analyze data, guide teachers and execute managerial duties. In other words, they now assume leadership roles especially among teachers (Helf \& Cooke, 2011).

In this sense, there is a need to identify the roles of reading specialists in schools with either strong or weak literacy programs. Schools with good reading programs have veteran reading specialists who have advanced education related to reading (Bean et al., 2003). Usually, these reading specialists engage with the following functions: instruction, advisor to teachers, act as an assessor, act as an intermediary between the school and the community, and supervise reading programs. On the other hand, schools with inadequate literacy programs have experienced teachers who act as consultants yet have either limited to nil exposure to literacy consultation (Deussen et al., 2007).

Notwithstanding, various studies also expose that the functions and duties of a reading specialist are diversed and hitherto has become more budding and cognizant in relation to its environment and contemporary power-relations (Haab, 2001). This is supported by Sarno-Tedeschi (1991) who shows that apart from being a remedial teacher, a reading specialist also has more or less 15 other duties that are affected by pervading acknowledge power and authority. In addition, the concurrent culture in the 
institution influences the duties performed by remedial reading teachers which is further coupled by their personal strengths and weaknesses (Darwin, 2002).

Therefore, due to the ambiguity of the character and functions of remedial reading instructors added with the concurrent institutional culture of their workplace, they have assumed a multifaceted set of responsibilites which could or could not aid them in developing the literacy skills of the students in their schools. As this confusion regarding their roles show no signs of abating, it would appear that a uniform job description is not feasible, if not impossible. Nevertheless, in the lack of a collective and binding definition of their roles, the expectations of people who work with them or learn from their instruction have become more significant than ever in this quest of understanding.

\section{Perspectives regarding Remedial Reading Teaching}

Perspectives vis-à-vis oneself, others, or ideas heavily affect the behavior and performance of an individual in any given setting (Charon, 2009; Isenberg, 2010; Stryker, 2010). Subsequently, remedial reading teachers and those who they interact with have their own perspectives about reading instruction (Thompson, 1979). In other words, the beliefs they have about themselves and the assumed perceptions of others affect the manner on how they confront their responsibilities. These set of beliefs influence their set of goals in the aspect of working, instruction, and administrative roles they undertake. Most in the academe, further, claim that discords regarding perspectives on roles correlate to the ineffectivity of programs (Rupley, Mason, \& Logan, 1985)..

There is barely sufficient literature about perspectives regarding remedial reading teaching but the majority of these studies revolve around the point-of-views of reading specialists about their own roles and have indicated the complexity and fluidity of their responsibilities (Frost, 2007). In the study of Serafini (2005), it shows that there are three elements which affect the perspectives of remedial reading teachers: (1) administrative support; (2) rapport with classroom; and (3) literacy foundation and the level of experience. Moreover, their knowledge and experience can also be viewed by their colleagues to determine their reliability and credibility.

In other words, reading specialists' perspectives of themselves are influenced by the expectations of others. For example, if reading specialists are viewed as remedial reading teacher as in the case in the Philippines, they would perform duties principally for the development of the reading skills of struggling students; if they are perceived as a resource person for teachers, they would render assistance to teachers as needed; and if they are considered as collaborative consultants, they are expected to improve the professional literacy instruction of teachers (Frost, 2007).

Notwithstanding these perspectives, a multitude of studies have indicated that reading specialists have assumed the role of an instructor in remedial reading programs than that of a consultant i.e. working with students who have difficulties in reading (Barclay \& Thistlewaite, 2012: Crain, 2003; Kulesza, 2001; Quatroche, Bean, \& Hamilton, 2001;). This is due to the notion that reading specialists are engineers who are tapped whenever there are reading problems among students (Jaeger, 2016). That is to say, the predominant role of reading specialists is remedial instruction where they spend majority of their time (Bean et al., 2002).

In the study of Barclay and Thistlewaite (2012), it reveals a ten to one ratio for those who assume teaching roles as compared to those who perform as consultants. This 
is supported by Kulesza (2001) who discovered that among elementary level reading specialists, instruction is their primary role alocating $94 \%$ of their time to remedial classes while only $6 \%$ perceived the role of a resource person as the most important. This is further supplemented by Crain (2003) who found out that reading specialists view their role as teachers for students who are inadequate in literacy skills as their fundamental duty. Albeit, they also asserted that there is a need to broaden their job operation i.e. the things they do and for whom they do it.

Nevertheless, other studies have also indicated that consultative and collaborative functions are more important (Lapp et al., 2003; Darwin, 2002; Haab, 2001; Henwood, 2000). This did not, however, imply that assisting struggling students are no longer relevant rather the focus has been redirected to the development of the teachers' instructional competencies. The study of Henwood (2000) asserts that through collaborative efforts between reading specialists and classroom teachers, the needs of students in literacy can be covered. In her study, she immersed herself in the secondary level working directly not with students but with teachers. By working with the latter, she has pointed out the improvement in their instructional strategies which also met the literacy needs of the students.

There has been a shift of focus towards a more collaborative role for reading specialists since the 1980s. In other words, there is a need for both reading specialists and teachers to work together. Several features have been determined to achieve successful collaboration: common vision, dispersal of power, positive interaction, and dedication (David \& Handler, 2001). The key for an effective collaborative work between reading specialists and teachers are the following: (1) possibility of reading specialists to collaborate with others; (2) explicit guidelines; (3) deliberation of guidelines; (4) creation of reading models that can work for each group; (5) group or grade levels meetings to disclose the assessment results for enhancing the flexibility of each groups (Guth \& Pettengill, 2005).

There are two components which can aid in establishing rapport and credibility: exchanges of similar content disciplines and having shared goals (Frost, 2007). In the aspect of content-area, most reading specialists come from English or other language subjects as it is noted to have been mostly engaged in literacy instruction (Draper et al., 2005). However, there could be conflicts in applying language-based methods to subjects that vary completely from English such as Science or Mathematics.

To achieve this shared goal of improving the literacy of students is to be embrace the idea of: Every teacher is a teacher of reading. This stems from the concept in the 1920s that if teachers aim at developing the reading skills of their students by applying it in their various lessons, the remedial reading class would be unnecessary (Barry, 1994). Furthermore, the achievement of a common goal can be done through the involvement of classroom teachers in planning and the interpretation of assessments conceived by reading specialists (Jaeger, 2016). However, the reality is otherwise; reading specialists hitherto undertake the role of teaching, thus they are being called as remedial reading teachers (Stauffer, 1967).

This special role of teaching reading specialists have assumed is further augmented by the difficulty of classroom teachers to craft their own lessons that have both the content of their subjects and the literacy skills which are needed to be developed by the students (Ivey \& Fisher, 2005). This predicament is assumed to be the cause of the polarity of content literacy and content reading. The former pivots around the students as the creator of knowledge protruded by various creative tasks but are not 
parallel with their subject. The latter, on the other hand, is concerned with the teachers and written works which the students extract through the traditional manner of instruction (O'Brien, Stewart, \& Moje, 1995). In spite of these, Draper et al. (2005) argue that this duplexity is fallacious. That is to say, literacy development is not confined to a single subject e.g. English or Filipino but should be present in all subject areas.

Administrators or principals having the monopoly of influence and resources, indubitably, are integral to the success of reading programs (Bean et al., 2003). It is a fact mainly because administrators direct the flow of resources of the institution from one program to another i.e. if a principal supports a remedial reading teacher in his programs, failure would clearly seem to be out of the option. Nonetheless, literatures regarding administrators are minimal.

Bean et al. (2003) examined the perspectives of principals about reading specialists. $97 \%$ of principals from 39 schools in the U.S. assented that the latter should be engaged in assessment, diagnosis, and instruction. They also signify the importance of reading specialists in the accomplishment of school programs about reading skills. Kulesza (2001), on the contrary, viewed the perspectives of administrators through the lense of the experiences of reading specialists. Her study posited that principals compel them to perform a plethora of roles, to wit, making them a jack of all trades from crafting a standardized test to enabling them to work independently. Such practice is also mirrored in the Philippines as Alayon (2014) revealed in his study that majority of remedial reading teachers in the Philippines are expected to do jobs that are out of what was bestowed to them.

The study of Bean, Trovato and Hamilton (2010) sums up the perspectives of reading specialists, teachers and principals. The first group view subject teachers as the primary instructors in the classroom and play an important role in decision-making in relation to teaching. However, they are discontented with their changing roles in education as there seems to be vagueness in their functions and responsibilities in first place. The second group proved to have a positive view on reading specialists as experts in terms of reading instruction and in the making of reading programs. The third group is determined by both the other groups as indispensable in the institutionalization of strong and enduring reading programs. That is to say, their perspectives matter in the program-making.

There is indeed the need to develop the skills and abilities of reading specialists. Thus, the ILA (2010) mandates all reading specialists to exhibit competence in all the six established standards namely foundational knowledge, curriculum and instruction, assessment and evaluation, diversity, literate environment, professional learning and leadership (ILA, 2010). These standards imply that the most prominent role of a reading specialist remain to be in the instruction or the assessment of students, but research may say otherwise and identify training in teacher leadership, collaboration and coaching to be the primary goal.

Most of the reading specialists start as classroom teachers and then go on to attain advanced training in literacy so it is important for universities to be wary of how their programs prepare reading specialists. Helfrich and Bean (2011) identified coursework and field experience to be crucial parts of these programs since they enable teachers to apply theoretical knowledge in the field. Making sure that teachers get to connect coursework to their fieldwork, hence, is beneficial. Literacy consultants must have a 
good grasp on different aspects of literacy and be able to operate effectively with teachers (L'Allier, Elish-Piper \& Bean, 2009).

There are several findings on how reading specialists can be prepared to work with struggling readers (Allington, 2013). Research reveals that specialists frequently ask struggling readers to read passages which are too hard for them, producing only opposite results, and they often assign less reading works to struggling readers compared to their more successful counterparts. Reading specialists' skills should be enhanced through trainings and experiences that focus on strategies to actively engage struggling readers in reading in a less frustrating context.

Reading specialists must be trained to instruct struggling readers and to assist teachers in all three levels of teaching namely: Level 1 which is informal coaching, Level 2 which pertains to more formal coaching with needs assessment, and Level 3 which refers to formal coaching (Bean, 2009). Moreover, Shaw (2007) reports that exposing candidates to literacy coaching assignments within the three levels of coaching has a huge impact in producing effective reading specialists.

\section{CONCLUSION AND SUGGESTION}

Just like any other profession, it is essential for teachers to cultivate their full potentials in order to provide quality service and for them to perform well in their work. Based on the reviewed literatures, it is clear that remedial reading teachers need to develop the necessary knowledge and skills that they should have. The growth of a remedial reading teacher is affected by several factors and that these factors are in most cases intertwined with another. Remedial reading teachers need to understand all these factors as core components of the whole teaching experience so that they will be able to reflect on their own professional needs.

It is clear that the trajectory of the developments and role attributions of remedial reading teachers have been in a constant change and transformation eversince the job title came into existence. The cultivation of the roles and duties of remedial reading teachers rely so much on different factors, some of which are knowledge and the skills that remedial reading teachers have, philosophical views in education of the teachers and the whole school community, the rapport that remedial reading teachers have with their colleagues, the support of the administrators to their personal and career developments, provisions of the government in fostering remedial reading teachers' experiences and skills, and many more.

In the Philippines, the roles and duties of remedial reading teacher or reading specialist is not even clear on the end of the teachers. This is evident since there is a limited amount of local studies focusing on remedial reading teachers. Their roles are usually broad and thus, they are forced to perform tasks which in the first place should have not been theirs. Notably, some research findings exuded that in most cases, the job descriptions and roles of remedial reading teachers are a mismatch. The absence of role specificity and concreteness amalgamate the struggles of remedial reading teachers in doing their jobs in schools effectively. Several studies also revealed that the perceptions of remedial reading teachers' colleagues immensely affect how they enact their roles in schools.

It is important to note that the way remedial reading teachers assume their roles vary. Majority of them believe that their primary, if not their sole role in schools is to provide assistance and instruction to students with reading difficulties. For some, they see themselves as consultants hence, limiting their roles and functions in their 
institutions. Although, there has been a minimal number of studies referring to how school administrators affect the cultivation of remedial reading teachers' roles and experiences, these studies viewed them as more of instructors. Eventhough there is rarity of literature and studies, it appears that the essential factor in concretizing how reading specialists or remedial reading teachers function in school is their own perceptions about their roles and professional experiences.

Barrow (2017) gave new related foreign literature to help reading professionals better understand intervention for young children with reading difficulties. However, it is evident that there is a paucity of research undertaking in the Philippines that focused on on remedial reading teachers. In fact, elementary schools and high schools in the country are designing and implementing their own reading programs but no exploration has been made as to what would it take to develop the full potentials of remedial reading teachers. Just like any other profession, it is important for every remedial reading teacher to understand what they need to go through and what they need to experience in order to solidify their understanding of their duties in their respective institutions. As this is becoming clear, part of the loophole in the local context is also the scarcity of unravelling the roles and functions of remedial reading teachers. Therefore, there is a vital need to explore on the what's and the how's of remedial reading teachers in a hope of creating clear policies that will support their developments. Such explorations may also lead to the concretization of their roles and duties which set them apart from other classroom reading teachers in Philippine schools.

\section{REFERENCES}

Alayon, D.P. (2014). Utilizing SQ3R method in enhancing the reading proficiency of junior high school learners (unpublished master's thesis). National Teacher's College, Manila, Philippines.

Allington, R. L. (2013). What really matters when working with struggling readers. The reading teacher, 66(7), 520-530.

Barclay, K. D., \& Thistlewaite, L. (2012). Reading specialists of the '90s: What do they want? Reading, Research and Instruction (32), 87-96.

Barry, A. (1994). The staffing of high school remedial reading programs in the United States since 1920. Journal of Reading (38), 14-22.

Barry, A. (1997). High school reading programs revisited. Journal of Adolescent \& Adult Literacy (40), 524-531.

Batan, A.D. (2016). Examining the problems encountered by elementary remedial reading teachers in Batangas (unpublished master's thesis). University of Batangas, Philippines.

Bean, R. M. (2009). Role of the reading specialist: A multifaceted dilemma. Reading Teacher (32), 409-413.

Bean, R. M., \& Eichelberger, R. T. (2015). Changing the role of the reading specialists: From pull-out to in-class programs. Reading Teacher, 648-653

Bean, R. M., Swan, A. L., \& Knaub, R. (2003). Reading specialists in schools with exemplary reading programs: Functional, versatile, and prepared. Reading Teacher (56), 446-456.

Bean, R. M., Trovato, C., \& Hamilton, R. (2010). Focus on chapter 1 reading programs: Views of reading specialists, classroom teachers, and principals. Reading Research and Instruction (34), 204-221. 
Bean, R., Cassidy, J., Grumet, J., Shelton, D., \& Wallis, S. (2002). What do reading specialists do? Results from a national survey. Reading Teacher, 736-745.

Brownell, M. T., \& Walther-Thomas, C. (2000). An interview with Dr. Michael Pressley. Intervention in school \& clinic (36), 105-108.

Charon, J. M. (2009). Symbolic Interactionism. Englewood Cliffs, New Jersey: Prentice-Hall.

Crain, A. B. (2003). Role of the reading specialist: Perspectives of content area teachers and reading specialists. Atlanta: Georgia State University

Darwin, M. J. (2002). Delving into the role of the high school reading specialist.

Fairfax, Virginia: George Mason University.

David, R., \& Handler, M. (2001). The many faces of school-university collaboration. Englewood, CO: Teacher Ideas.

Deussen, T., Coskie, T., Robinson, L., \& Autio, E. (2007). Coach" can mean many things: Five categories of literacy coaches in reading first (Issues \& Answers Report, REL 2007-No. 005). Washington, DC: US Department of Education, Institute of Education Sciences. National Center for Education Evaluation and Regional Assistance, Regional Educational Laboratory Northwest. Retrieved from http://ies. ed. gov/ncee/edlabs.

Dietrich, D. M. (2007). Standards and qualifications for reading specialists. Reading Teacher (20), 483-489.

Draper, R. J., Smith, L. K., Hall, K., \& Siebert, D. (2005). What's more important literacy or content? Confronting the literacy-content dualism. Teacher in Action Education (27), 12-21.

Frost, L. L. (2007). A multiple-case study of secondary reading specialists. Utah: Bringham Young University.

Gates, V. V. (2014). Competencies that count among reading specialists. Journal of Reading (17), 608-613.

Gener, L.S. (1976). Exploring the implementation of remedial reading programs in the Philippines (unpublished doctoral dissertation). University of Sto. Tomas, Manila, Philippines.

Guth, J.K, \& Pettegil, R. (2005). Teacher Training and Classroom Discipline. In K. Wheldall, Discipline in Schools: Psychological Perspectives on the Elton Report. London: Taylor and Francis.

Haab, M. (2001). The emergent nature of the role of a reading specialist: A study of the sociopolitical forces that shape the role of a reading specialist. Philadelphia: University of Pennsylvania.

Habagat, J.P \& Rizon, E.R. (2012). Narrating the experiences of remedial reading teachers Cebu city. Philippine Quarterly of Culture and Society, 40: 12-22

Hamilton J. O. (2001). Preventing reading failure: A review of five effective programs. The Reading Teacher (92), 30-39.

Helf, S., \& Cooke, N. L. (2011). Reading specialist: Key to a systematic school wide reading model. Preventing School Failure, 55(3), 140-147.

Helfrich, S. R., \& Bean, R. M. (2011). Beginning teachers reflect on their experiences being prepared to teach literacy. Teacher Education and Practice, 24(2), 201222.

Henwood, G. F. (2000). A new role for the reading specialist: Contributing toward a high school collaborative educational culture. Journal of Adolescent \& Adult Literacy (43), 316-325. 
Hutson, B. A., McDonnel, \& Fortune, J. C. (2012). A multifaceted view of the roles of the reading specialist. National Reading Conference. Clearwater, Florida.

International Literacy Association. (2004). The role and qualifications of the reading coach in the United States: A position statement of the International Reading Association. Newark, Delaware: Author.

International Literacy Association. (2010). Teaching all children to read: The roles of the reading specialist. A position statement of the International Reading Association. Newark, Delaware: Author.

Isenberg, J. P. (2010). Teachers' thinking and beliefs and classroom practice. Childhood Education (66), 322-327.

Ivey, G., \& Fisher, D. (2005). Learning from what doesn't work. Educational Leadership (63), 8-14.

Jaeger, E. L. (2016). The reading specialist as collaborative consultant. The Reading Teacher (49), 622-629.

Kern, D. (2011). 62 years of the pendulum's swing: The role of the reading specialist. New England Reading Association Journal, 46(2), 67.

Kulesza, D. (2001). The role of reading specialists: A descriptive study. Las Vegas: University of Nevada.

L'Allier, S., Elish-Piper, L., \& Bean, R. M. (2009). What matters for elementary literacy coaching? Guiding principles for instructional improvement and student achievement. The Reading Teacher, 63(7), 544-554.

Lalunio, G.M (1994). Factors that affect teacher attrition in the National Capital Region (unpublished doctoral dissertation). Pamantasan ng Lungsod ng Maynila, Philippines.

Lapp, D., Fisher, D., Flood, J., \& Frey, N. (2003). Dual role of the urban reading specialist. Journal of Staff Development (24), 33-36.

Mason, G. E., \& Palmatier, R. A. (1973). A preparation for professionals in reading. Journal of Reading (16), 637-640.

Miguel, S. (2007). Needs analysis of elementary teachers in the school division of Quezon city. (unpublished master's thesis). Centro Escolar University, Philippines.

Moburg, L. G. (1967). A new consultant gets started. Reading Teacher (20), 520-524.

Montalban, A.V. (2010). Reading difficulties of grade 6 pupils of a public schools in Manila. (Unpublished master's thesis). University of the East, Philippines.

Mosby, E. M. (2002). An analysis of job descriptions for reading specialists in selected school districts in the United States. Texas: Texas A \& M University.

O'Brien, D. G., Stewart, R. A., \& Moje, E. B. (1995). Why content literacy is difficult to infuse into the secondary school: Complexities of curriculum, pedagogy, and school culture. Reading Research Quarterly (30), 442-463.

Quatroche, D. J., Bean, R. M., \& Hamilton, R. L. (2001). The role of the reading specialist: A review of research. The Reading Teacher (55), 282-294.

Readence, J. E., Baldwin, R. S., \& Dishner, E. K. (2008). Establishing content reading programs in secondary schools. Reading Teacher, 523-527.

Rio, A.H. (2007), The roles of remedial reading teachers in the province of Samar: a narrative inquiry. Philippine Quarterly of Culture and Society, 33, 27-42.

Rio, A.H. (2017), Levels of awareness of remedial reading teachers on their roles. Philippine Quarterly of Culture and Society, 61, 1-14.

Robinson, H. (1958). The secondary school reading specialist. Reading Teacher(12), 
103-106.

Robinson, H. (1967). The reading consultant of the past, present, and possible future. Reading Teacher (20), 475-482.

Robinson, R. D., \& Petit, N. T. (2008). The role of the reading teacher: Where do you fit in? Reading Teacher (31), 923-927.

Ruddell, M. (1993). Teaching content reading and writing. Needham Heights, Massachusetts: Allyn \& Bacon.

Rupley, W. H., Mason, G., \& Logan, J. W. (1985). Past, present, and future job responsibilities of public school reading specialists. Reading World, 48-60.

Sarno-Tedeschi, J. M. (1991). The roles of the reading specialists in the culture of high school: A tapestry of perceptions, politics, possibilities. New York: Columbia University.

Serafini, F. S. (2005). The evolving role of the reading (literacy) specialist. National Reading Conference. San Antonio, Texas.

Shaw, M. L. (2007). Preparing Reading Specialists to Be Literacy Coaches: Principles, Practices, Possibilities. Journal of Language and Literacy Education, 3(1), 6-17.

Stauffer, R. G. (1967). Change, but-. Reading Teacher (20), 474-499.

Stryker, S. (2010). Symbolic interactionism: A social structural version. Menlo Park, California: Benjamin/Cummings Publishing.

Tatum, A. W. (2004). A road map for reading specialists entering schools without exemplary reading programs: Seven quick lessons. Reading Teacher (58), 28-39.

Thomas, E. L. (2009). A reading consultant at the secondary level. Reading Teacher, 509-514.

Thompson, M. E. (1979). Remedial college freshmen English students: Description and characteristics. Reading Horizons: A Journal of Literacy and Language Arts, 19(3), 15.

Umali, M. (2016). The Reading Difficulties of Grade III Pupils in District IV in the Schools Division of Manila. Manila: Philippine College of Health Sciences, Inc.

Vacca, J. L., \& Padak, N. D. (1990). Reading consultants as classroom collaborators: An emerging role. Journal of educational and psychological consultation (1), 99- 107.

Vogt, G. L., \& Shearer, D. A. (2007). Rockets: teacher's guide with activities in science, mathematics, and technology. Final Report, Teaching From Space Program NASA Johnson Space Center, Houston, TX.

Walpole, S., \& McKenna, M. C. (2004). The literacy coach's handbook: A guide to research-based reform. New York, NY: Guilford 